\title{
Energy and flux variations across thin auroral arcs
}

\author{
H. Dahlgren 1, ${ }^{1,}$ B. Gustavsson ${ }^{2}$, B. S. Lanchester ${ }^{2}$, N. Ivchenko ${ }^{1}$, U. Brändström ${ }^{3}$, D. K. Whiter ${ }^{2,4}$, T. Sergienko ${ }^{3}$, \\ I. Sandahl ${ }^{3}$, and G. Marklund ${ }^{1}$ \\ ${ }^{1}$ Space and Plasma Physics, School of Electrical Engineering, KTH, Stockholm, Sweden \\ ${ }^{2}$ School of Physics and Astronomy, University of Southampton, UK \\ ${ }^{3}$ Swedish Institute of Space Physics, Kiruna, Sweden \\ ${ }^{4}$ Finnish Meteorological Institute, Helsinki, Finland \\ *now at: Dept. of Electrical and Computer Engineering and Center for Space Physics, Boston University, USA
}

Received: 16 February 2011 - Revised: 10 August 2011 - Accepted: 27 September 2011 - Published: 4 October 2011

\begin{abstract}
Two discrete auroral arc filaments, with widths of less than $1 \mathrm{~km}$, have been analysed using multi-station, multimonochromatic optical observations from small and medium field-of-view imagers and the EISCAT radar. The energy and flux of the precipitating electrons, volume emission rates and local electric fields in the ionosphere have been determined at high temporal (up to $30 \mathrm{~Hz}$ ) and spatial (down to tens of metres) resolution. A new time-dependent inversion model is used to derive energy spectra from EISCAT electron density profiles. The energy and flux are also derived independently from optical emissions combined with ion-chemistry modelling, and a good agreement is found. A robust method to obtain detailed 2-D maps of the average energy and number flux of small scale aurora is presented. The arcs are stretched in the north-south direction, and the lowest energies are found on the western, leading edges of the arcs. The large ionospheric electric fields $\left(250 \mathrm{mV} \mathrm{m}^{-1}\right)$ found from tristatic radar measurements are evidence of strong currents associated with the region close to the optical arcs. The different data sets indicate that the arcs appear on the boundaries between regions with different average energy of diffuse precipitation, caused by pitch-angle scattering. The two thin arcs on these boundaries are found to be related to an increase in number flux (and thus increased energy flux) without an increase in energy.
\end{abstract}

Keywords. Atmospheric composition and structure (Airglow and aurora) - Ionosphere (Auroral ionosphere; Particle precipitation)

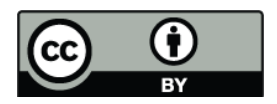

Correspondence to: $\mathrm{H}$. Dahlgren (hannad@bu.edu)

\section{Introduction}

High resolution imaging of aurora borealis from the ground has revealed the inherent occurrence of small scale structuring, with auroral filaments of widths of just a few tens of metres appearing on time scales of a fraction of a second (Maggs and Davis, 1968; Borovsky et al., 1991; Trondsen and Cogger, 2001). A recent review of small scale structures in aurora and their importance was presented by Sandahl et al. (2008). Small-scale features occur in all types of aurora, however, the distribution of energy and flux in space and time of the electron precipitation causing these structures has been hard to establish. Observations from the Freja spacecraft and simultaneous ground-based imagers showed a close correspondence between the optical brightness of auroral arcs and the particle flux (Frey et al., 1998). In a study of a very bright auroral structure, Lanchester et al. (1997) found that the largest energy flux was within a narrow filament of about $100 \mathrm{~m}$ width, caused by monoenergetic particles with a large flux. This filament was located within a wider region of lower energy flux and with a broad energy distribution. Multi-spectral observations of thin auroral arcs have shown that such filaments can also be the result of high energy precipitation within a region of lower energy precipitation. Dahlgren et al. (2008) showed two arc filaments appearing within a few seconds of each other, where the first was a result of precipitation with higher energy whereas the second arc was caused by increased particle flux.

Ground-based multi-spectral imaging of the aurora combined with ionospheric modelling is a well developed method to determine the variation of energy and flux of auroral arcs (Strickland et al., 1989; Meier et al., 1989; Hecht et al., 1989; Gustavsson et al., 2001; Semeter et al., 2001). A 2-D map of the energy can be derived from optical observations made at two different wavelengths, close to magnetic zenith. From multi-station observations, tomography-like reconstruction can also be made, to produce a 3-D image of the volume

Published by Copernicus Publications on behalf of the European Geosciences Union. 

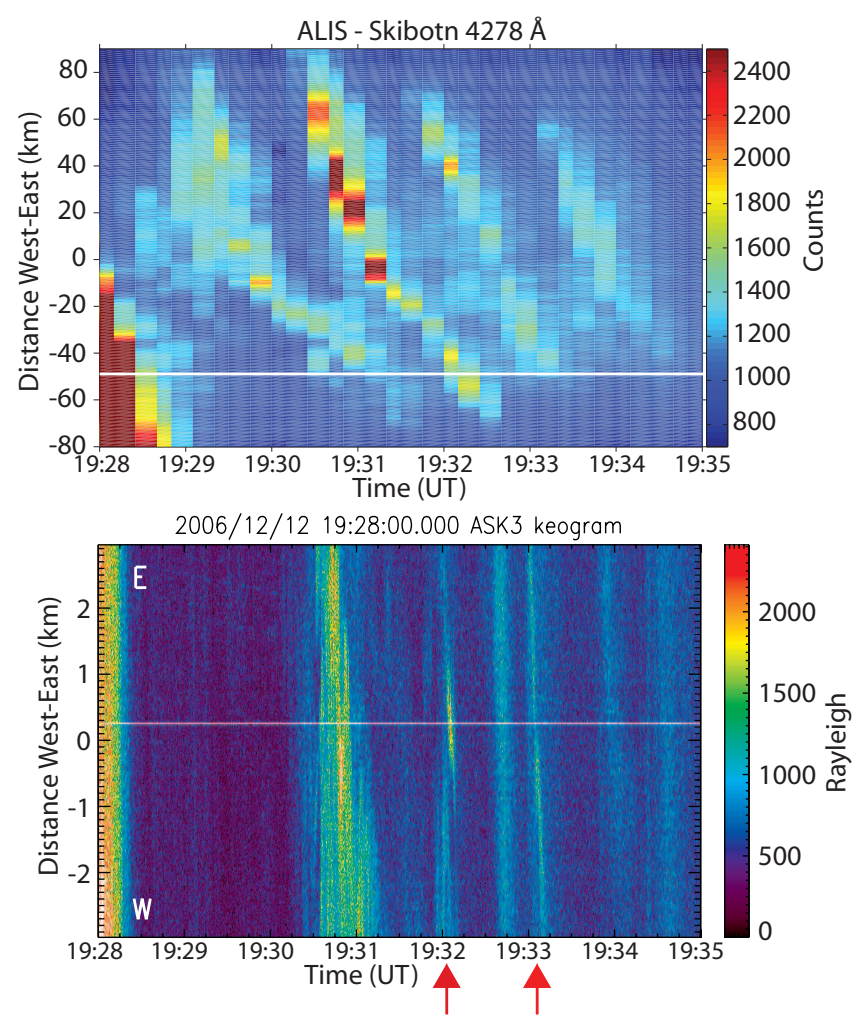

Fig. 1. Top panel: east-west keogram from the ALIS imager in Skibotn, for the time interval 19:28-19:35 UT. Bottom panel: eastwest ASK keogram from the same time interval. The white lines mark the position of the EISCAT beam at $107 \mathrm{~km}$ altitude.

emissions of the aurora (e.g. Aso et al., 1998). These methods are used in this report, to determine the nature of two thin auroral arcs.

In this study, results from a new ion-chemistry inversion model, based on a time dependent iterative method inverting incoherent scatter radar (ISR) data to spectra of the primary precipitating electrons, and high resolution optical data of fine scale aurora have been used to determine the spectra of the precipitating electrons causing two thin auroral arcs. We show that the results from the inversion model are in good agreement with the observed ISR and optical data and can be used in the characterisation of auroral features. The two arcs are found to be the result of increased number flux on the boundary between regions of diffuse aurora with different average energies.

\section{Instrumentation}

Optical measurements were carried out with the Auroral Large Imaging System (ALIS) and Auroral Structure and Kinetics (ASK). The ASK instrument consists of three lowlight EMCCD detectors, with optical systems providing a field of view (FOV) of $3.1^{\circ} \times 3.1^{\circ}$. The three imagers are co- aligned with identical FOVs. The frame rate is $32 \mathrm{~Hz}$ and the cameras are equipped with narrow passband $(\Delta \lambda \sim 10 \AA)$ interference filters, selecting emissions from the $\mathrm{O}_{2}{ }^{+} 1 \mathrm{~N}$ band at $5620 \AA\left(\mathrm{I}_{\mathrm{O}_{2}^{+}}\right.$, measured with ASK1), the forbidden oxygen ion at $7320 \AA\left(\mathrm{I}_{\mathrm{O}^{+}}\right.$, measured with ASK2) and atomic oxygen at $7774 \AA$ ( $\mathrm{I}_{\mathrm{O}}$, measured with ASK3) (Dahlgren et al., 2008). Only data from ASK1 and ASK3 are used in this study. At the time of these observations ASK was positioned at the EISCAT site in Ramfjordmoen $\left(19.2^{\circ} \mathrm{E}, 69.6^{\circ} \mathrm{N}\right)$, pointing towards magnetic zenith.

Five ALIS stations with approximately $50 \mathrm{~km}$ separation were operating during this study, from Kiruna $\left(20.4^{\circ} \mathrm{E}\right.$, $\left.67.8^{\circ} \mathrm{N}\right)$, Silkimuotka $\left(21.7^{\circ} \mathrm{E}, 68.0^{\circ} \mathrm{N}\right)$, Abisko $\left(18.8^{\circ} \mathrm{E}\right.$, $\left.68.4^{\circ} \mathrm{N}\right)$, Tjautjas $\left(20.8^{\circ} \mathrm{E}, 67.3^{\circ} \mathrm{N}\right)$ and Skibotn $\left(20.4^{\circ} \mathrm{E}\right.$, $\left.69.4^{\circ} \mathrm{N}\right)$. At each station a sensitive CCD camera with a FOV of $70^{\circ}$ or $90^{\circ}$ was operating (Brändström, 2003). The auroral light passed through narrow passband $(\Delta \lambda=40 \AA$ or $50 \AA$ ) interference filters before reaching the detectors. A filter wheel was alternating between the auroral emission lines at $5577 \AA\left(\mathrm{O}\left({ }^{1} \mathrm{~S}_{0}\right)\right), 6300 \AA\left(\mathrm{O}\left({ }^{1} \mathrm{D}_{2}\right)\right), 8446 \AA\left(\mathrm{O}\left({ }^{3} \mathrm{P}_{0,1,2}\right)\right)$ and $4278 \AA\left(\mathrm{N}_{2}^{+}\right)$, making $2 \mathrm{~s}$ exposures every $5 \mathrm{~s}$, and giving time resolutions of $10-40 \mathrm{~s}$, with the highest resolution for the $5577 \AA$ and $4278 \AA$ filters. At the time of interest, four of the five ALIS stations had clear skies, which made tomography-like inversions (Gustavsson, 1998) of the 3-D distribution of volume emission rate possible.

The EISCAT UHF radar was operating the arc1 experiment. Arc1 uses a 64-bit alternating code and gives decoded measurements of the ionospheric electron density, electron and ion temperatures and field-aligned ion drift with $4.4 \mathrm{~s}$ time resolution and electron density estimates from returned power profiles with $0.44 \mathrm{~s}$ time resolution and $0.9 \mathrm{~km}$ range resolution. The receivers in Kiruna and Sodankylä were also in use, providing tristatic measurements of the ion drift at $220 \mathrm{~km}$ altitude over Ramfjordmoen, from which the 3-D electric field is derived.

\section{Event description}

On 12 December 2006 bright aurora appeared in the magnetic zenith over the EISCAT site. A substorm onset took place at about 19:20 UT with $\mathrm{Kp}=3$. A video of the substorm from the ALIS imager at Skibotn can be downloaded from the auxiliary material. An overview of the time evolution of activity taking place in the magnetic zenith between 19:28 UT and 19:35 UT is shown in Fig. 1, in which the top panel is the $\mathrm{N}_{2}^{+}$emission at $4278 \AA$ occurring in an east-westdirected cut through the Skibotn ALIS images. The white horizontal line marks the position of the EISCAT beam at $107 \mathrm{~km}$ altitude. The ordinate is the horizontal distance from the camera pointing direction, where east is at the top and west at the bottom. The bottom panel is a similar keogram from the ASK3 imager, for $\mathrm{I}_{\mathrm{O}}$. Structured and highly dynamic aurora was present in the ASK FOV between 19:30:30 

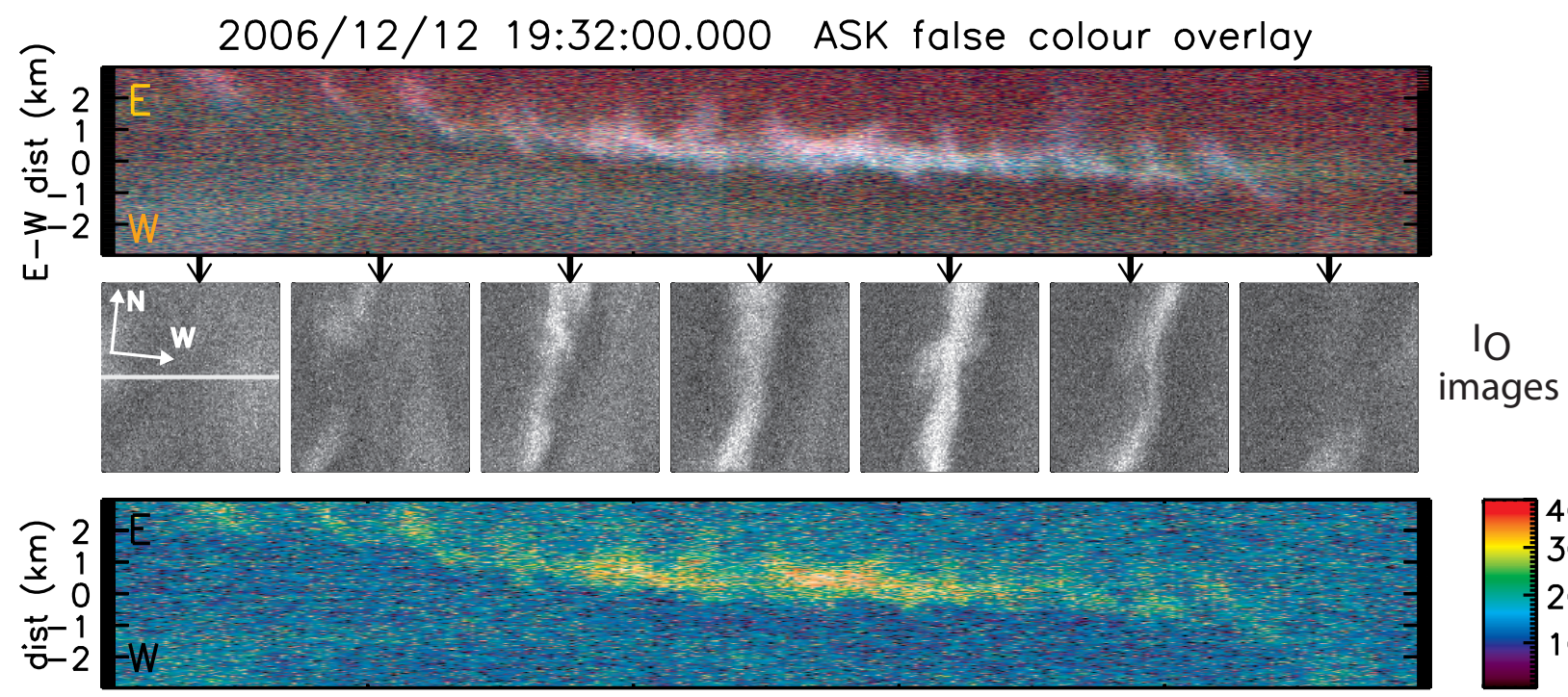

400

300

$200+2$

100
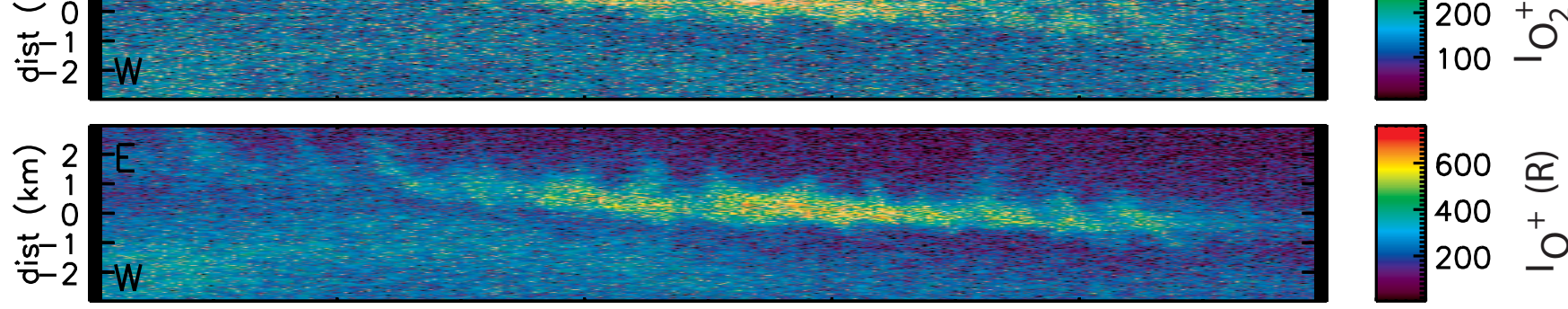

600

400
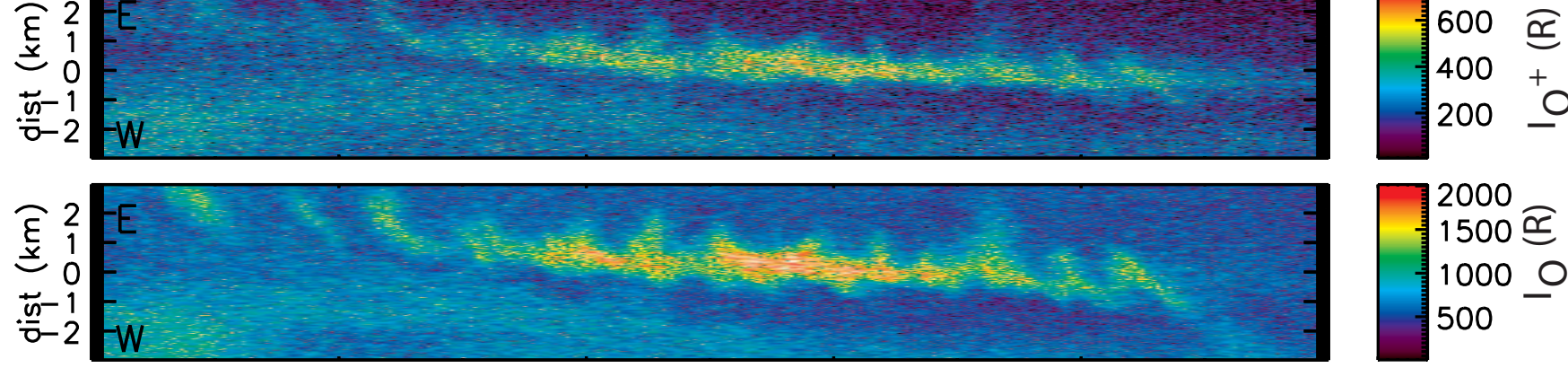

2000 $1500 \cong$ 10000 19:32:02

$19: 32: 04$

$19: 32: 06$

$19: 32: 08$

$19: 32: 10$

Fig. 2. ASK keograms from the arc passing the FOV at 19:32 UT. The bottom three keograms are from ASK1 (I $\left.\mathrm{O}_{2}^{+}\right)$, ASK2 ( $\left.\mathrm{I}_{\mathrm{O}^{+}}\right)$and ASK3 $\left(I_{O}\right)$, and the top keogram is a colour-coded (red-green-blue) overlayed keogram of the three channels. All keograms are made from east-west aligned cuts through the images. $\mathrm{I}_{\mathrm{O}}$ images for different times are shown below the overlayed keogram.

and 19:31:15, but will not be discussed further here. Two thin north-south aligned arcs drifted through the EISCAT beam after 19:32 UT and 19:33 UT, respectively. A more diffuse arc could also be seen in ASK between these two arcs, at 19:32:40 UT. The present study is the analysis of the thin, well-defined arcs at 19:32 UT and 19:33 UT, marked with arrows in Fig. 1.

For the auroral arc at 19:32 (hereafter referred to as the 1932 arc), detailed keograms and images are displayed in Fig. 2. The top panel shows a colour-coded overlaid keogram, with $\mathrm{I}_{\mathrm{O}_{2}^{+}}$in red, $\mathrm{I}_{\mathrm{O}^{+}}$in green and $\mathrm{I}_{\mathrm{O}}$ in blue, created from an east-west (horizontal) cut in the images. The second panel contains $\mathrm{I}_{\mathrm{O}}$ images for the keogram interval, to show the full auroral evolution. The position of the keogram cut is indicated with a horizontal line in the first image. Panels 3, 4 and 5 are the individual keograms for $\mathrm{I}_{\mathrm{O}_{2}^{+}}, \mathrm{I}_{\mathrm{O}^{+}}$and $\mathrm{I}_{\mathrm{O}}$. Shear is noted on the arc at the time of the observations, with enhancements moving to the south (down in the images) on the eastern (left) side of the arc, and north (up) on the west- ern (right) side. A $10 \mathrm{~s}$ video of the 1932 arc at 32 frames/s can be downloaded from the auxiliary material. When in the magnetic zenith, the full width half maximum (FWHM) of the arc varies between $0.2-1.3 \mathrm{~km}$ at an assumed height of $100 \mathrm{~km}$. The variation is due to the shear motions along its length, with an average width of $750 \mathrm{~m}$. The ripples have amplitude of $1 \mathrm{~km}$, wavelength of $5 \mathrm{~km}$ and velocity of $9 \mathrm{~km} \mathrm{~s}^{-1}$.

One minute later, another filamentary auroral arc, referred to as the 1933 arc, moved through magnetic zenith to the west with an average velocity of $1 \mathrm{~km} \mathrm{~s}^{-1}$ as shown in Fig. 3 (same format as Fig. 2). The arc has an average FWHM of $850 \mathrm{~m}$ in the magnetic zenith. Shear motion is not as prominent and dynamic as one minute earlier, and the optical brightness is also lower. Emissions in all three ASK imagers indicate that for both events there is a broad energy spectrum of precipitating electrons.

Figure $4 \mathrm{a}$ is an ALIS image of $\mathrm{N}_{2}^{+}$at $4278 \AA$ taken from Skibotn at 19:32 UT. The ASK FOV mapped to $110 \mathrm{~km}$ is marked as a red box. The structured, extended north-south aligned arc seen just to the east of the box is the 1932 arc (to 


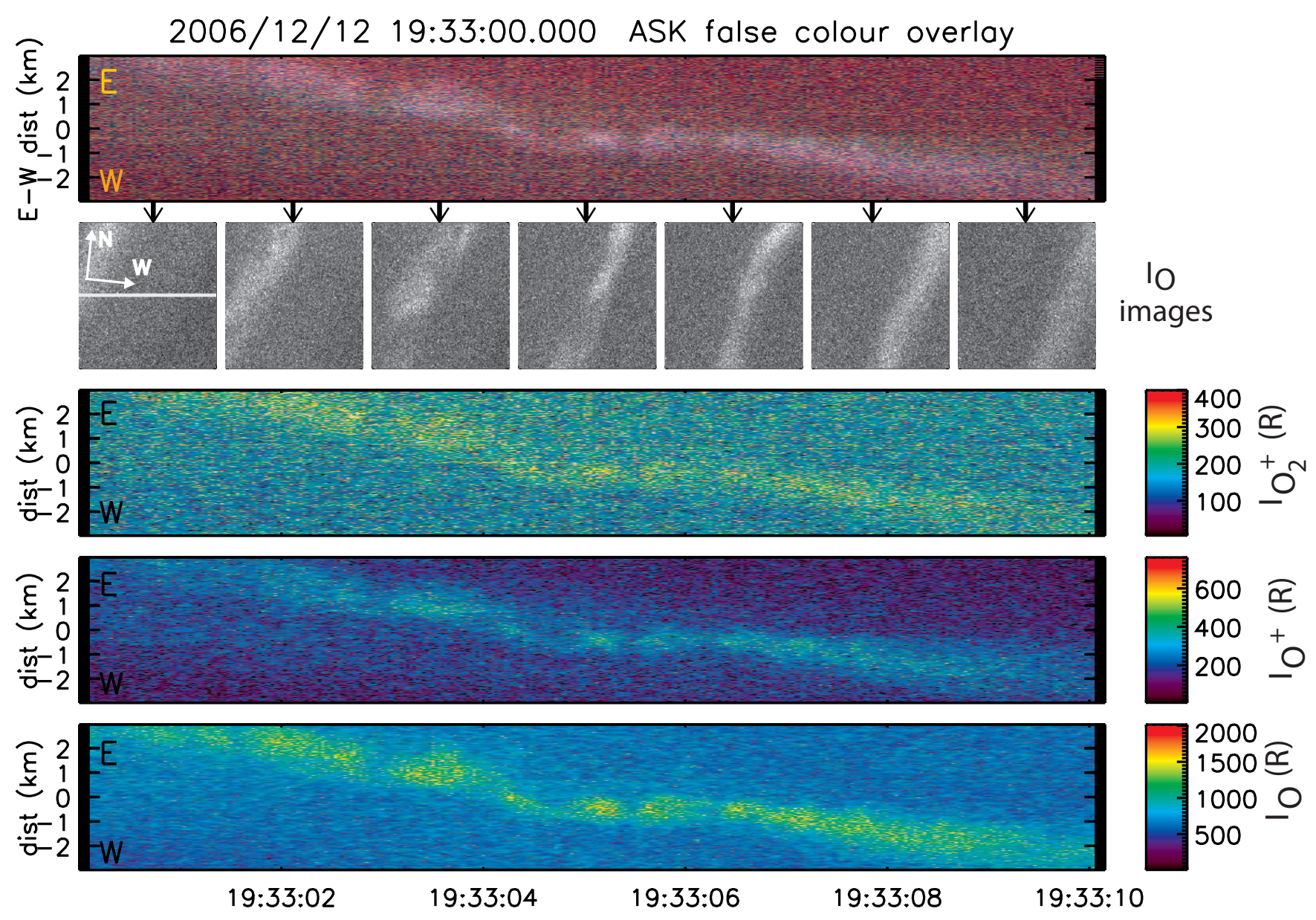

Fig. 3. ASK keograms from the arc passing the FOV at 19:33 UT. The bottom three keograms are from ASK1 ( $\left.\mathrm{I}_{2}^{+}\right)$, ASK2 ( $\left.\mathrm{I}_{\mathrm{O}^{+}}\right)$and $\operatorname{ASK} 3\left(\mathrm{I}_{\mathrm{O}}\right)$, and the top keogram is a colour-coded (red-green-blue) overlayed keogram of the three channels. All keograms are made from east-west aligned cuts through the images. $\mathrm{I}_{\mathrm{O}}$ images for different times are shown below the overlayed keogram.

the right in the figure). The wider unstructured arc to the west of this arc corresponds to the diffuse emissions appearing in ASK only a few seconds before the 1932 arc. The 1932 arc shows evidence of rays, seen as intensifications along the arc. The 1933 arc can be seen further to the east in the figure. The projected location of Ramfjordmoen and Skibotn are marked with a red dot and a blue cross, respectively. The arcs appear much wider in the ALIS image from Skibotn than in ASK due to perspective effects. This imager is located $50 \mathrm{~km}$ east of Ramfjordmoen, so is imaging aurora $35^{\circ}$ from the magnetic zenith at ASK and EISCAT.

A false colour overlay of $\mathrm{I}_{\mathrm{O}_{2}^{+}}$(red), $\mathrm{I}_{\mathrm{O}^{+}}$(green) and $\mathrm{I}_{\mathrm{O}}$ (blue) from ASK is shown in Fig. 4b. The size and position of the radar beam is marked with a circle. The beam has a width of $0.6^{\circ}$, corresponding to approximately $1 \mathrm{~km}$ at $100 \mathrm{~km}$ altitude. The narrow arc drifts into the ASK FOV from the east, passing magnetic zenith and continuing to the west, with a drift velocity of about $540 \mathrm{~m} \mathrm{~s}^{-1}$. At the end of the passage the prompt emission moves rapidly to the west, leaving behind an afterglowing $\mathrm{O}^{+}$emission in ASK2. The afterglow of this event has been analysed in Dahlgren et al. (2009), who found that the emission decay history was consistent with $1 \mathrm{keV}$ precipitation.

\section{Results}

In this section the methods and main results are presented. A description of how 2-D energy maps can be obtained from the optical data and modelling is given in Sect. 4.1. Section 4.2 introduces the inversion model used together with radar measurements to estimate energy and flux profiles of the precipitation. From the multi-point observations made by the ALIS network, the volume emission rates can be reconstructed, which is described in Sect. 4.3, and in Sect. 4.4 this information is combined to present a coherent formation model of the observed aurora. Section 4.5 finally relates this model to the electric field estimates derived from the EISCAT tristatic measurements. 
(a)

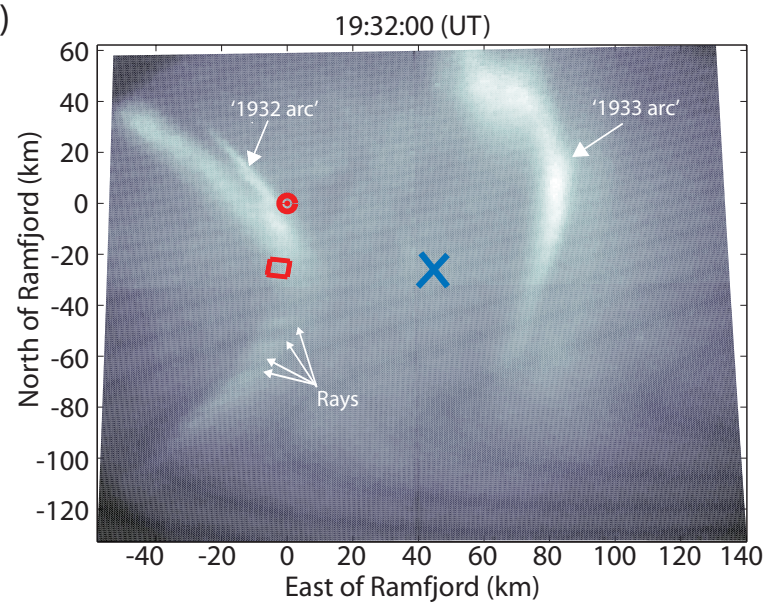

(b)

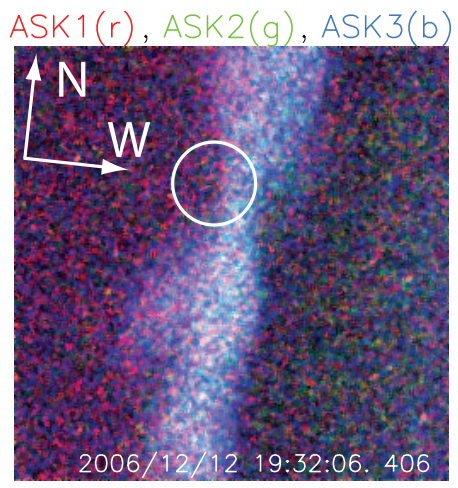

Fig. 4. (a) ALIS image taken from Skibotn at 19:32:00 UT. The FOV of ASK at $110 \mathrm{~km}$ altitude is marked with a red box. The location of Ramfjordmoen and Skibotn are marked as a red dot and a blue cross, respectively. The 1932 and 1933 arcs discussed in this paper can both be seen at this time. (b) False colour overlay of $\mathrm{I}_{\mathrm{O}_{2}^{+}}$ (red), $\mathrm{I}_{\mathrm{O}^{+}}$(green) and $\mathrm{I}_{\mathrm{O}}$ (blue) from ASK, for the 1932 arc. The location of the radar beam is marked with a circle.

\subsection{Optical emission ratios}

Simultaneous measurements of $\mathrm{I}_{\mathrm{O}_{2}^{+}}$and $\mathrm{I}_{\mathrm{O}}$ provide a timedependent two-dimensional image of the changes in average electron energy of the precipitating electrons. $\mathrm{I}_{O}$ is mainly caused by direct electron impact excitation of atomic oxygen in the F-region and upper E-region. $\mathrm{I}_{O}$ is thus a good indicator of low energy electron precipitation. However, it is not a pure measure of low energy precipitation, as the excited state of the oxygen atom can also be reached by dissociative excitation of $\mathrm{O}_{2}$ in the E-region, caused by high energy precipitation. $\mathrm{I}_{\mathrm{O}_{2}^{+}}$is produced by electron impact ionisation of $\mathrm{O}_{2}$ and since $\mathrm{O}_{2}$ has a shorter scale height than $\mathrm{O}$, the $\mathrm{O}_{2}^{+} 1 \mathrm{~N}$ emission requires electron precipitation with energy deposition at lower altitudes, that is, with higher energy, compared to atomic oxygen. The ratio $\mathrm{I}_{\mathrm{O}_{2}^{+}} / \mathrm{I}_{\mathrm{O}}$ can therefore be used to map the characteristics of the precipitation.
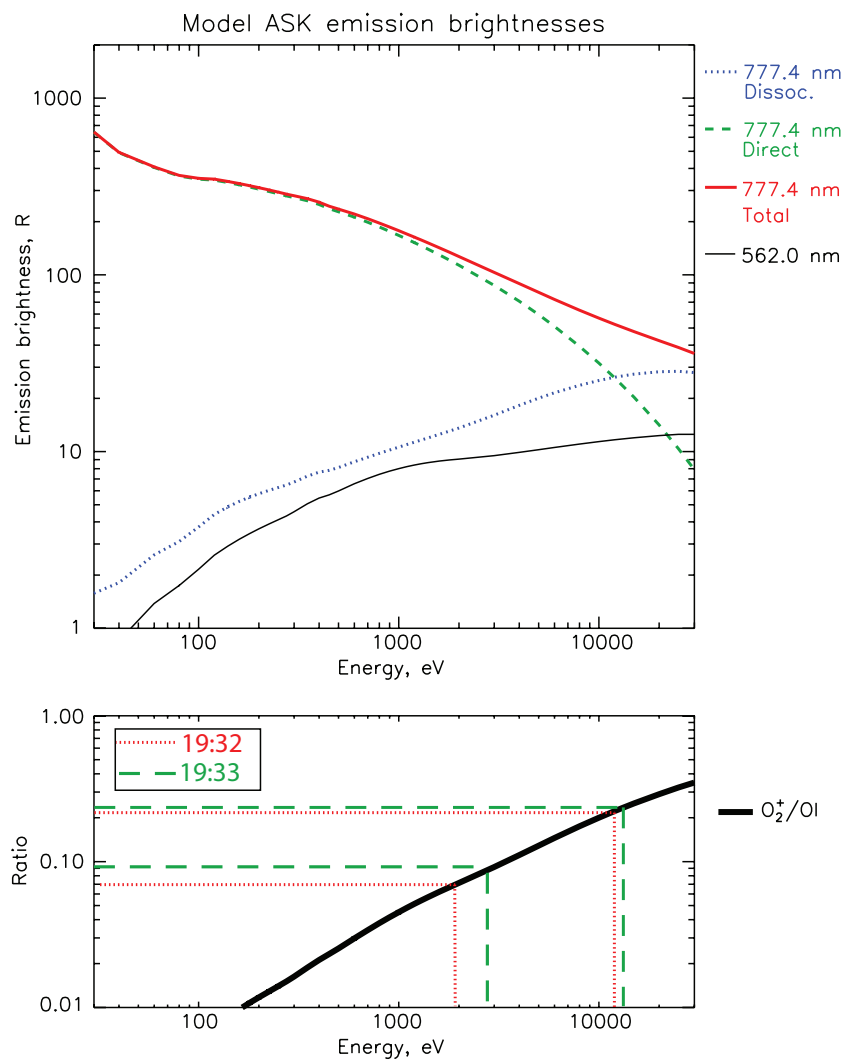

Fig. 5. Top: modelled emission brightness versus energy for the ASK emissions. Bottom: modelled emission ratio versus energy (black). The minimum and maximum ratios are plotted as red dotted lines for the 1932 arc, and as green dashed lines for the 1933 arc.

The average energies of the precipitating electrons corresponding to different ASK emission ratios have been modelled with the Southampton ion chemistry and electron transport model (described in detail in Lanchester et al., 1994, 1997) with atmospheric parameters for the conditions of the night of interest. Figure 5 (top) shows how the emission brightness varies with energy of precipitation for the emissions observed with ASK1 and ASK3. The result is produced by assuming a Gaussian distribution with a constant energy flux of $1 \mathrm{~mW} \mathrm{~m}^{-2}$ and increasing energy. Note that the contribution to $\mathrm{I}_{\mathrm{O}}$ from dissociation of $\mathrm{O}_{2}$ increases with energy whereas direct excitation decreases rapidly with energy increase. The total emission brightness closely follows the direct excitation curve. The total modelled emission brightness of the $\mathrm{O}_{2}^{+}$band was multiplied by a factor 0.0633 to account for the reduction of emission passing through the ASK1 filter. The bottom panel of Fig. 5 shows the resulting variation in $\mathrm{I}_{\mathrm{O}_{2}^{+}} / \mathrm{I}_{\mathrm{O}}$ vs. energy, which is used in this study to derive the energy of the precipitation based on ASK emissions.

The left column of Fig. 6 shows the variation of $\mathrm{I}_{\mathrm{O}_{2}^{+}}$(dotted) and $\mathrm{I}_{\mathrm{O}}$ (dashed) together with the ratio $\mathrm{I}_{\mathrm{O}_{2}^{+}} / \mathrm{I}_{\mathrm{O}}$ (black) taken along a cut through the images at five times during the 
1932 arc
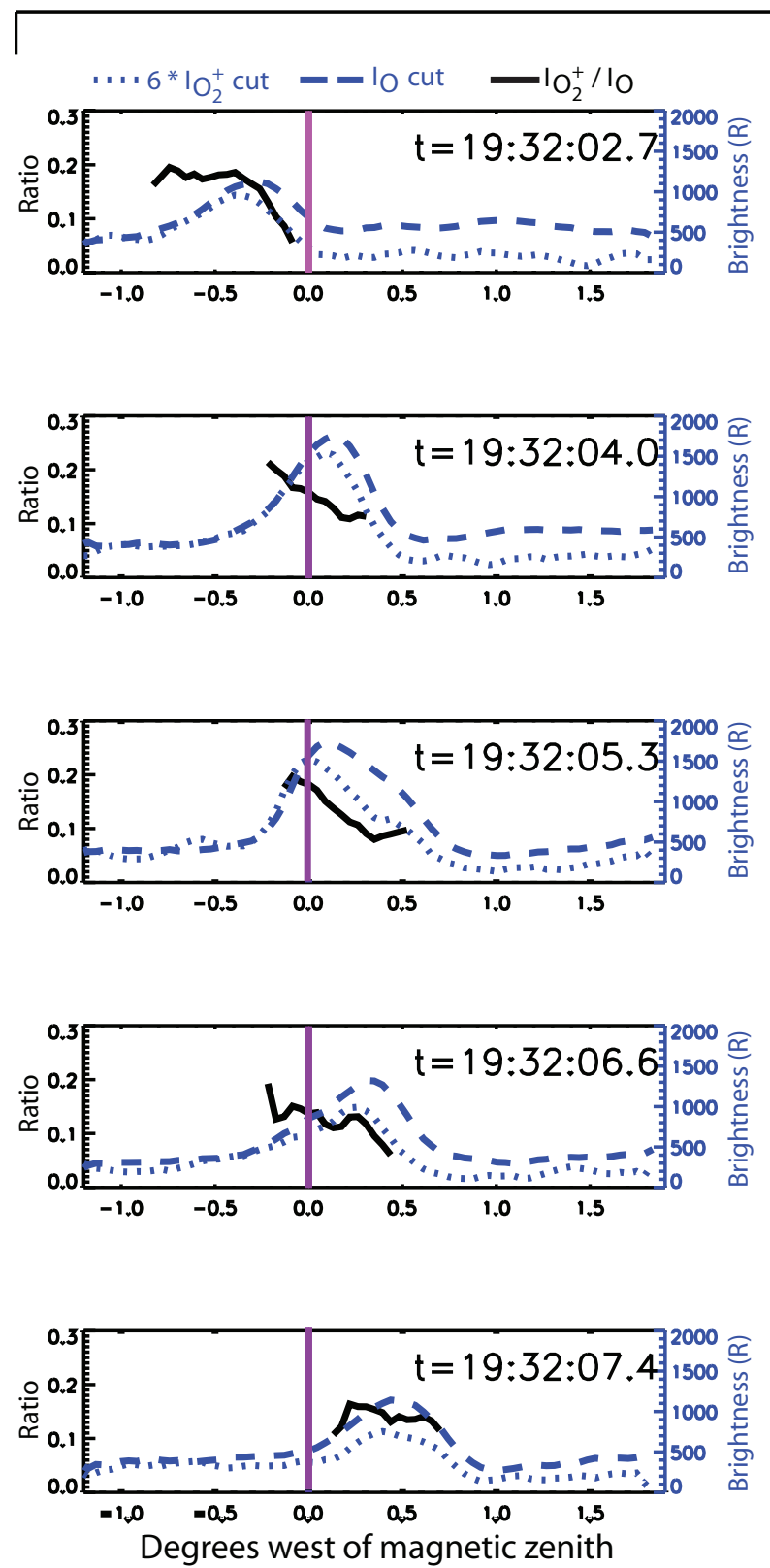
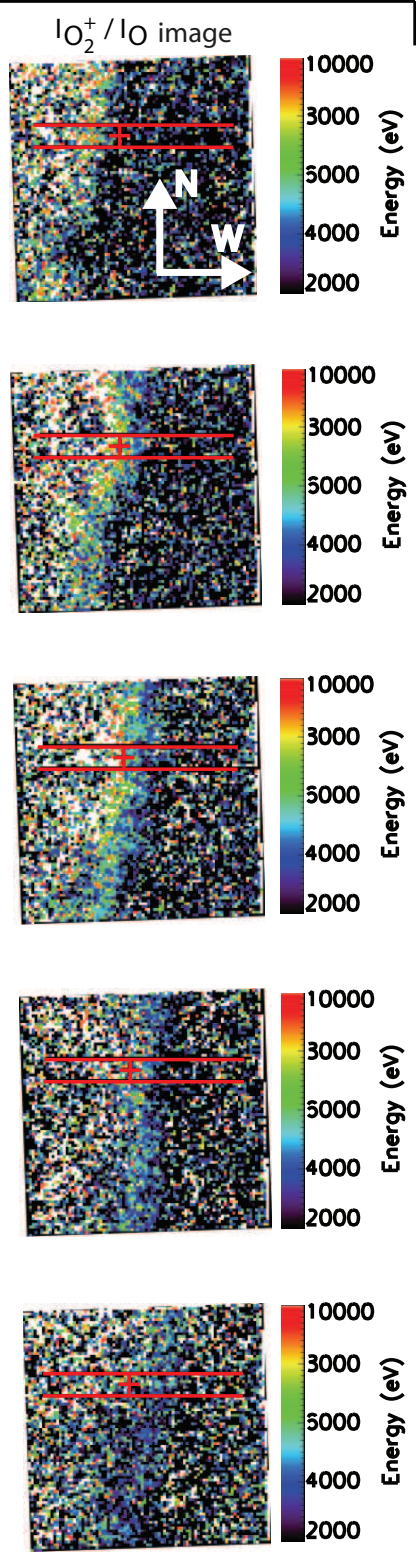

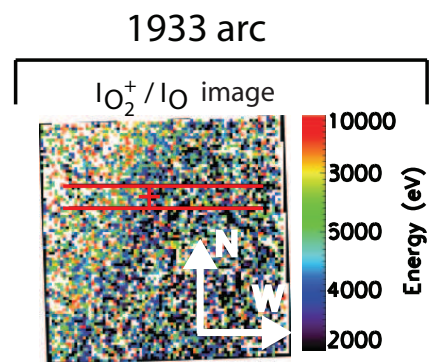

19:33:02.8

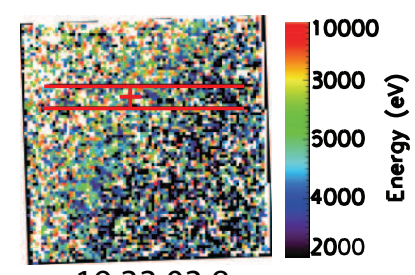

19:33:03.8

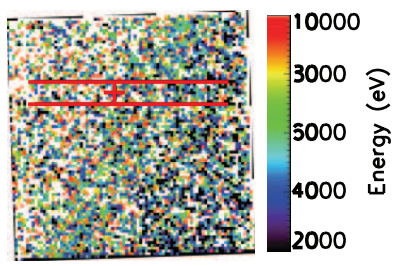

19:33:02.8

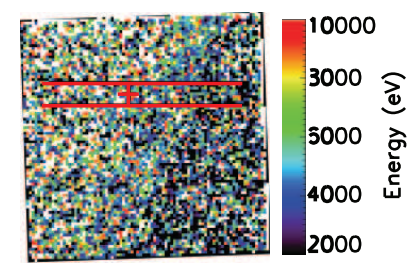

19:33:02.8

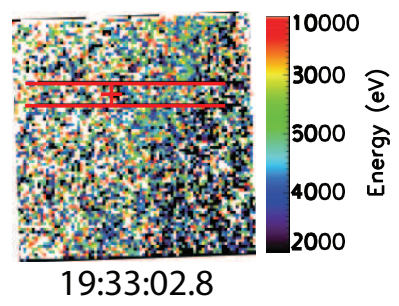

Fig. 6. Left: $\mathrm{I}_{\mathrm{O}_{2}^{+}}$(blue dotted line), $\mathrm{I}_{\mathrm{O}}$ (blue dashed line) and $\mathrm{I}_{\mathrm{O}_{2}^{+}} / \mathrm{I}_{\mathrm{O}}$ (black) from cuts made through the ASK images at 19:32 UT. Middle: $\mathrm{I}_{\mathrm{O}_{2}^{+}} / \mathrm{I}_{\mathrm{O}}$ images, giving a 2-D distribution of the energy of the precipitating electrons. The red horizontal lines mark the region of the cut. Magnetic zenith is marked with a cross. Right column: 2-D energy distributions for the 1933 arc.

passage of the 1932 arc. The east-west aligned cut is through the magnetic zenith, and 8 pixels in the north-south direction are averaged to give a larger SNR. This region is shown by two horizontal lines in the images to the right, with the magnetic zenith shown as a cross. The images in the middle and right columns in Fig. 6 are derived 2-D maps of the average energy at the selected times for the 1932 and 1933 arc, respectively. The intensity of the 1933 arc is weaker, espe- cially for $\mathrm{I}_{\mathrm{O}_{2}^{+}}$(at most $130 \mathrm{R}$, compared to $200 \mathrm{R}$ for the 1932 arc), making the emission ratio for this arc more sensitive to noise. Note that a scaling factor of 6 has been used for $\mathrm{I}_{\mathrm{O}_{2}^{+}}$in the left-hand panels, where magnetic zenith is marked with a vertical line.

The largest values of the ratio $\mathrm{I}_{\mathrm{O}_{2}^{+}} / \mathrm{I}_{\mathrm{O}}$ are found on the eastern edge of the arc, with ratios of more than 0.2 , corresponding to average energies of more than $10 \mathrm{keV}$, and the 
smallest ratios appear on the western edge, where the energy of the precipitation is about $2-3 \mathrm{keV}$. The maximum and minimum ratios and energies for the 1932 and 1933 arcs, estimated across the east-west aligned cut marked in red in Fig. 6, are given in Fig. 5 by the red dotted lines and green dashed lines, respectively. The ratio distributions in the two arcs are in general asymmetric during the seconds they are passing through the zenith, so that the energy of the precipitation across the arcs has its highest value on the eastern, or trailing, edges. The emission ratio is calculated only for values larger than a threshold value of $\mathrm{I}_{\mathrm{O}}$, to eliminate background noise.

Since $\mathrm{I}_{\mathrm{O}_{2}^{+}}$is more efficiently excited in the ionospheric Eregion, while $\mathrm{I}_{\mathrm{O}}$ is more efficiently excited in the F-region, one can expect perspective effects when viewing the aurora off zenith (Semeter et al., 2008). In the region around magnetic zenith, the atomic oxygen emission seen by ASK3 is expected to appear closer to zenith, as it originates from higher altitudes, than the ASK1 emissions from the molecular oxygen ions at lower altitudes. In the first panel of Fig. 6 the $\mathrm{I}_{\mathrm{O}}$ (blue dashed curve) is shifted towards magnetic zenith compared with the $\mathrm{I}_{2}^{+}$(blue dotted curve) at a time when the arc is to the east of zenith. But as the arc passes through zenith, $\mathrm{I}_{\mathrm{O}}$ does not remain closer to magnetic zenith, but continues peaking to the west of the $\mathrm{I}_{\mathrm{O}_{2}^{+}}$peak. This effect cannot be a product of perspective, and has to be explained by variation in average energy across the arc.

\subsection{EISCAT and modelling}

The EISCAT measurements provide an independent method to estimate the average energy of the precipitation. The measured electron density profiles obtained in the magnetic zenith are compared with the electron density derived from a novel model, in which the continuity equation for the electron density is integrated with ionization rates calculated from parameterized electron energy and flux spectra. The best-fitting electron spectra is then found by minimizing the difference between the measured and modeled electron density profiles, through a weighted least square method. By this method, an assumed a priori shape of the spectrum is not needed. Details of the model are given in the Appendix.

The EISCAT power profile data are shown in Fig. 7 (top). The times of the 1932 and 1933 arcs are marked in the figure. There is a clear electron density enhancement coupled to the observed auroral brightening at 19:32:05 UT. At this time the lower border of the E-region enhancement decreases from $105 \mathrm{~km}$ to about $100 \mathrm{~km}$. At 19:33:05 UT there is a further lowering of the border from $100 \mathrm{~km}$ to about $95 \mathrm{~km}$. The bottom panel in the figure shows the resulting electron density constructed through the inversion model.

The modelled spectrogram for the 1932 arc is given in the top panel of Fig. 8. At 19:32:03 UT the entrance of the 1932 arc into the EISCAT beam is identified as strong enhancements of flux for all energies between $500 \mathrm{eV}$ and a
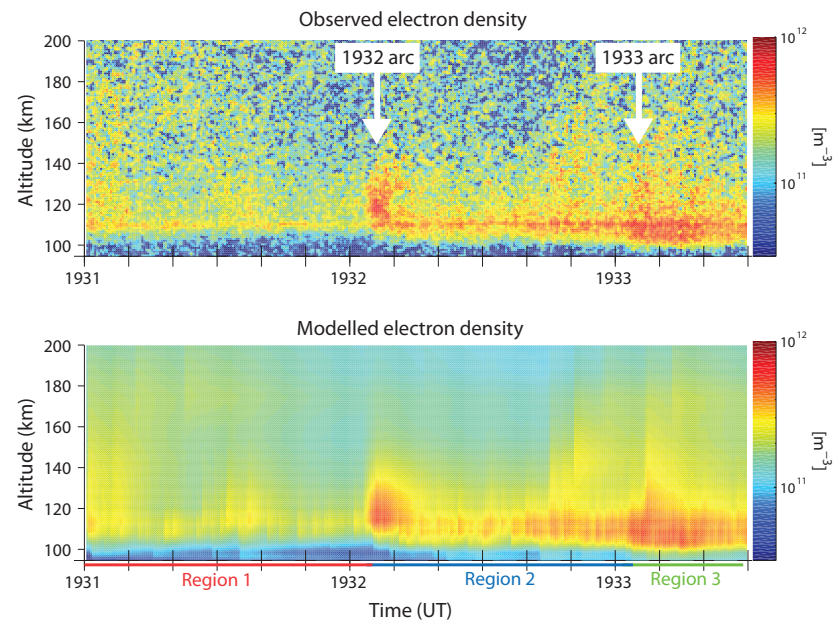

Fig. 7. Top: E-region enhancements in electron density corresponding to auroral arcs drifting over EISCAT. Bottom: modelled electron density.

few $\mathrm{keV}$. In the middle panel the average energy from the model is plotted as blue bars. The red line is the energy estimated from ASK emissions, which have been integrated over the area covered by the radar beam at $110 \mathrm{~km}$ altitude. The times when the arc is entering and leaving the radar beam are marked with blue shading, and the period when the arc is completely within the radar beam is marked by yellow shading. At the entrance of the 1932 arc into the radar beam the modelled average energy is $2.5 \mathrm{keV}$. During the passage of the arc, the energy increases to a steady value, with an average energy close to $5 \mathrm{keV}$. A very good agreement is found between the modelled energies and the energies obtained from ASK data. The bottom panel of Fig. 8 shows the modelled total electron energy flux (blue bars) with a maximum at the time when the arc is centered on the radar beam. The energy flux has also been derived from $\mathrm{I}_{2}^{+}$measured with ASK1 (red line). Figure 5 shows that for precipitation with energies of more than $1 \mathrm{keV}$ the emission brightness of $\mathrm{O}_{2}^{+}$(black line) is nearly constant for this emission, at about $10 \mathrm{R}$. The observed brightness can then be used as a proxy for energy flux. The fluxes agree well with the modelled fluxes from the EISCAT data, with values of more than $20 \mathrm{~mW} \mathrm{~m}^{-2}$.

The estimates of the energy and energy flux of the precipitation from the inversion model have been used, together with MSIS-90 neutral atmosphere parameters, as input into the Southampton ion chemistry and electron transport model. The time dependent model produces density profiles of the species of interest (and estimated emission brightnesses) for each time step. Volume emission rates have been modelled as a function of altitude for the $\mathrm{I}_{\mathrm{O}_{2}^{+}}$and $\mathrm{I}_{\mathrm{O}}$ emissions measured in ASK1 and ASK3 respectively, and a significant increase was found during the time when the arc was in the beam, with the peak of the emissions occurring at approximately 

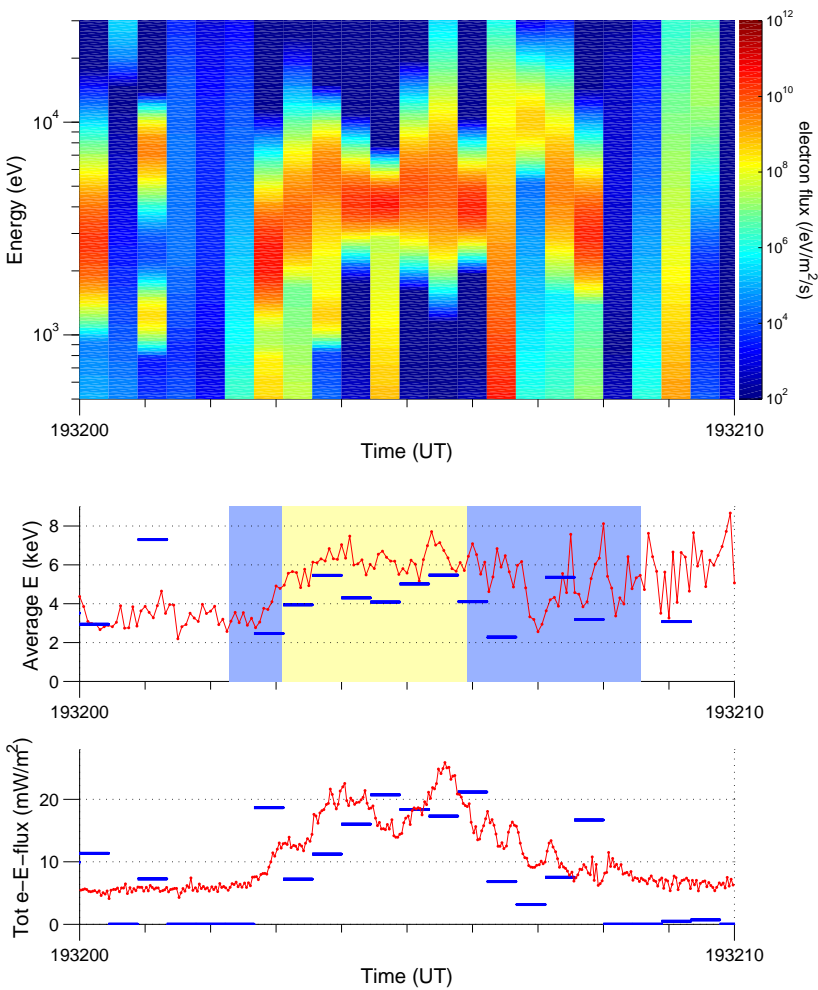

Fig. 8. Top: electron energy and flux spectrogram from the inversion model, for the arc at 19:32 UT. Middle: Average energy as a function of time derived from the model (blue bars) and from ASK emission ratios (red). Blue shaded regions are the time intervals the arc is moving into and out of the radar beam. The yellow shade is the time interval when the arc was located in the centre of the beam. Bottom: total electron energy flux as a function of time, from the inversion model (blue bars) and the ASK data (red).

$110 \mathrm{~km}$ altitude. The measured column brightness $B$ can be obtained by

$B=\frac{1}{10^{10}} \int \epsilon(z) \cdot d z$

where $\epsilon(z)\left(\mathrm{m}^{-3} \mathrm{~s}^{-1}\right)$ is the volume emission rate at altitude $z$, and $10^{10}$ is the conversion factor to Rayleigh, since $1 R=10^{10}$ photons $\mathrm{m}^{-2} \mathrm{~s}^{-1}$ (Hunten et al., 1956; Baker and Romick, 1976). The volume emission rates integrated in altitude from $100 \mathrm{~km}$ to $200 \mathrm{~km}$ give emission brightnesses of $360 \mathrm{R}$ for $\mathrm{I}_{\mathrm{O}_{2}^{+}}$(ASK1) and $4 \mathrm{kR}$ for $\mathrm{I}_{\mathrm{O}}$ (ASK3). These values can be compared with Fig. 2 where the 1932 arc has a maximum brightness of approximately $350 \mathrm{R}$ for ASK1 and $2 \mathrm{kR}$ for ASK3. The difference between the modelled and observed $\mathrm{I}_{O}$ could be caused by an overestimate of the $\mathrm{O}$ density in the MSIS atmosphere at auroral latitudes.

\subsection{Volume emission rates}

Three-dimensional volume emission rates of the $\mathrm{N}_{2}^{+}(1,0)$ emission at $4278 \AA$ have been estimated over a horizontal region of $130 \times 130 \mathrm{~km}$ between $80-260 \mathrm{~km}$ in height. This is done with a tomography-like inversion. Iteration of an initial guess with the multiplicative SIRT (Simultaneous Iterative Reconstruction Technique, Gordon and Herman, 1974; Gustavsson, 2000) algorithm is performed until no improvements are gained in the fit between the observed and the modelled images. For the initial guess an averaged altitude profile obtained from the model is used, which is then shifted and scaled based on the measured ALIS brightnesses.

The altitude variations of the volume emission rate for the 1932 and 1933 arcs are shown with solid lines in the top panel of Fig. 9. The maximum rates are found at $112 \mathrm{~km}$ and $102 \mathrm{~km}$ altitude, respectively. These peak altitudes agree well with those obtained from electron transport calculations with input spectra from the EISCAT inversion (dashed lines in the figure). Modeling of the 1933 arc is particularly difficult due to the low signal to noise ratio, which could introduce artifacts such as multiple peaks to the profile. The estimated volume emission rates derived from the ALIS images are approximately a factor 5-10 lower than what is obtained from the electron transport model. This is due to the horizontal widening of the auroral arcs to about $5 \mathrm{~km}$ in the estimates of the 3-D volume emission rates from ALIS data, so that the total number of emitted photons in the reconstructed arc is distributed over a wider volume. With more optical stations the accuracy and resolution of the volume emission distribution would be much improved. However, the good agreement of the peak altitudes and the altitude variations is an independent confirmation of the electron precipitation characteristics derived from EISCAT and ASK data. Due to the slower frame-rate of ALIS (one image per $5 \mathrm{~s}$ ) and the ALIS filter sequence used, the volume emission rate estimates from ALIS were made at 19:32:00 UT and 19:33:05 UT when the arcs were just outside the ASK field of view, shown with a black square in the lower panels in Fig. 9. However, it was especially difficult to identify the 1933 arc in the ALIS images. The brightest arc closest to the ASK FOV at this time was chosen for the estimate, meaning that the volume emission rate from ALIS could be overestimated. The arcs that were selected for the tomography estimates are shown with black crosses in the figures. Magnetic zenith above EISCAT and the ALIS Skibotn station are shown with red and blue circles.

\subsection{Characteristics of the precipitation}

Multi-monochromatic intensity ratio analysis of two thin auroral arcs stretched in the north-south direction gives the energy of precipitating electrons to be varying across the arcs, with the lower energies appearing on the western, leading edge. The precipitating electrons are found to have energies ranging from a few $\mathrm{keV}$ to approximately $10 \mathrm{keV}$. The energy estimates made by a new ISR data inversion algorithm show the same result, and indicate that coincident with the energy gradient across the arc is an increase in number flux. This 

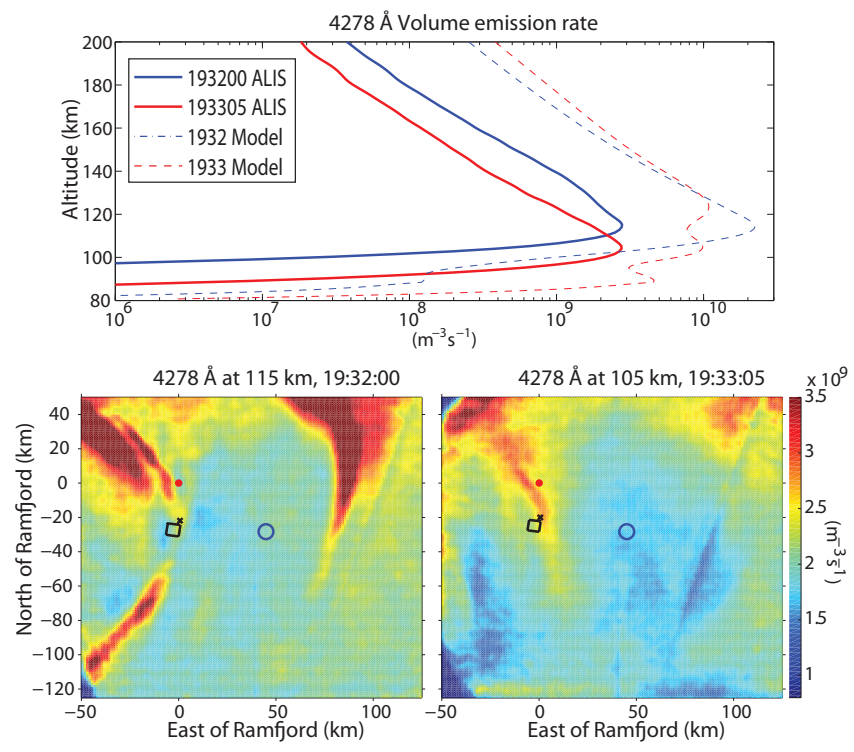

Fig. 9. Top panel: altitude profiles of the volume emission rates of the $\mathrm{N}_{2}^{+}(1,0)$ band derived from ALIS tomography data (solid lines), for the 1932 (blue) and 1933 (red) arcs, respectively. The modelled volume emission rates are shown as dashed lines. Bottom panels: Horizontal cuts for the narrow arcsat 19:32 UT and 19:33 UT.

flux increase is the signature that best can be coupled to the brightness of the arc.

The ALIS images show regions of diffuse background emission around these narrow arcs. The spatial scales of these regions are about $80 \mathrm{~km}$. The 2-D energy maps give regions of different energy in the image plane, with the northsouth arcs at the boundaries between them. We interpret the data as three different populations, with slightly different average energy of precipitation, within a region of diffuse aurora most likely caused by pitch-angle scattering. The region west of the 1932 arc is referred to as region 1, region 2 is the region between the arcs and region 3 is the region to the east of the $1933 \mathrm{arc}$. The regions drift through the EISCAT radar beam and at the boundaries between them, an increased flux appears, causing the north-south arcs. The effect is demonstrated in Fig. 10 where energy vs electron number flux from the inversion model is plotted in the top panel for the regions to the west (region 1) and east (region 2) of the 1932 arc, as well as for the time of the arc passage. The peak of the average energy is found to be about $4 \mathrm{keV}$ for region 1 and about $8 \mathrm{keV}$ for region 2 (see Fig. 8), so there is a clear shift in the energy distribution to higher energies for region 2 . The bottom panel shows a simple illustration of the 1932 arc and the two different regions surrounding it. The result is supported in all the data sets analysed. The EISCAT electron density (Fig. 7) shows a two-step decrease of the altitude of the lower border of the enhanced electron density, with the first decrease in altitude (hence increase in energy) occurring at the time of the 1932 arc and the second at the time
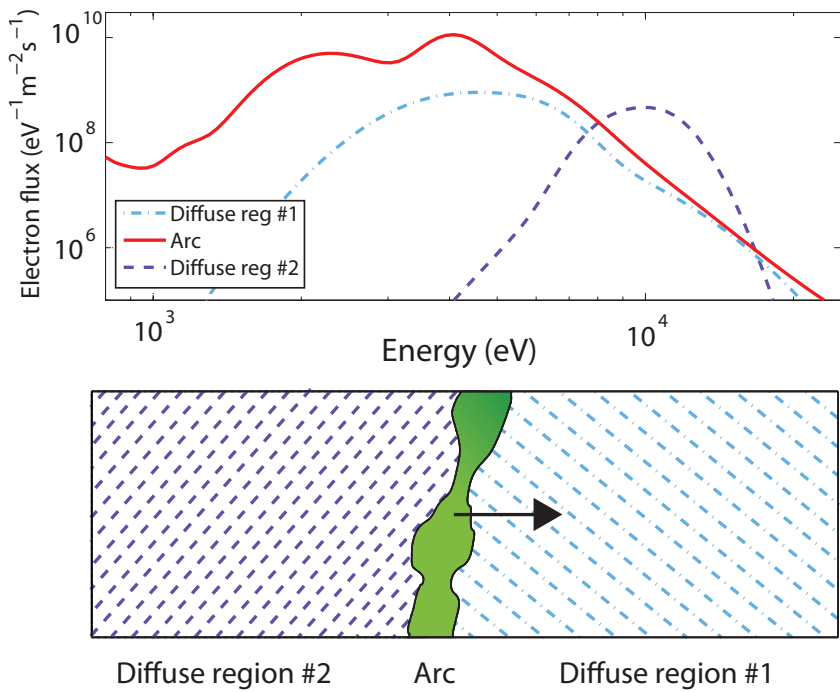

Fig. 10. Top: energy vs electron number flux derived from the inversion model, for the regions to the west of the arc (region 1), in the arc and to the east of the arc (region 2). Bottom: illustration of the 1932 arc and the two regions of different average energy surrounding it.

of the 1933 arc. The time intervals of the three regions are marked under the bottom panel. The overlaid keogram in Fig. 2 for the 1932 arc also shows low energy emission to the west of the arc (seen as green in the keogram), whereas high energy emissions are present to the east of the arc (red in the keogram). Emission ratio measurements from both the ASK and ALIS data sets confirm that the average energy is different in the three regions.

\subsection{Electric fields}

The EISCAT tristatic ion velocity measurements provide an estimate of the horizontal electric field in the beam, at $220 \mathrm{~km}$ altitude, over Ramfjordmoen. The north and west components of the electric field, analysed with a temporal resolution of $4 \mathrm{~s}$, for the time interval 19:28:00 UT-19:36:00 UT are plotted in blue and red respectively in the top panel of Fig. 11. The times when the 1932 and 1933 arcs are in the radar beam are shaded yellow. The electric field vectors are shown with arrows in the bottom panel. The electric field is found to rotate from predominantly south-southeast to north-northwest at 19:29:30 UT for about one minute, and then turns back to south-southeast again. The largest and most variable fields $\left( \pm 250 \mathrm{mV} \mathrm{m}^{-1}\right)$ are during the time of the 1932 and 1933 arcs, after which the field returns to the south-southeast direction again. The deviation of the estimated electric field components are indicated in the figure for each data point, and are relatively small. 

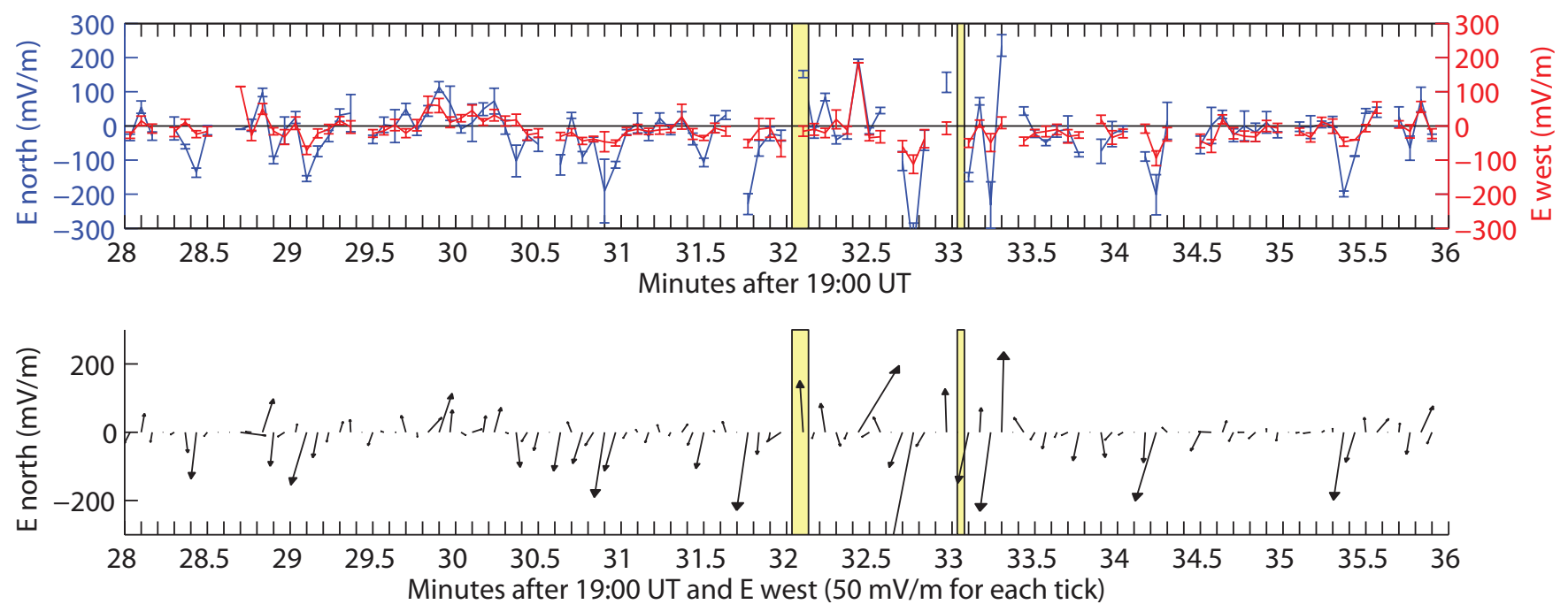

Fig. 11. Top: north and west components of the derived electric field from EISCAT, as a function of time. Bottom: direction and amplitude of the electric field vector at each instant of time.

\section{Discussion}

The combined optical and radar observations and modelling all indicate that the observed event consists of three regions of precipitation, producing diffuse aurora, with slightly different average energies, and that the two arcs appear on the boundary between these regions where an increase in number flux is found. The inversion of the radar data shows very low fluxes of low energy electrons (Fig. 10, top panel). This result suggests pitch-angle scattering of energetic electrons causing the diffuse aurora, rather than an electrostatic inverted-V structure, since an acceleration potential would reflect upflowing secondary electrons and provide a larger flux of downgoing low energy electrons. In a study of ALIS and FAST particle data, Sergienko et al. (2008) give examples of particle distributions resulting from both inverted$\mathrm{V}$ acceleration and wave interactions. Their Fig. 5 shows there is a low energy population associated with the particles accelerated by a potential structure, which is absent in the region of pitch-angle diffusion by electron cyclotron harmonic waves. The electron distribution in the present study matches well the FAST particle data at the time of pitchangle diffusion.

Kinetic magnetospheric modelling has shown that if the boundary between two plasma populations of differing densities and temperatures is parallel with the background magnetic field, the difference in ion gyroradii will set up an electric field across the boundary. These fields can be locally enhanced, leading to large parallel electric fields that can be associated with auroral arcs of widths as small as a fraction of a km (Roth et al., 1993). In the statistical study by Johansson et al. (2006), a correlation between plasma boundaries in the plasma sheet and bipolar electric fields was found. Such electric fields would then produce a velocity shear in the resulting arc due to the $\boldsymbol{E} \times \boldsymbol{B}$ drift. The electric fields estimated from the EISCAT data adjacent to the arcs of about $250 \mathrm{mV} \mathrm{m}^{-1}$ are more likely to be underestimated than overestimated, due to the spatial and temporal averaging effect of the radar data. Such strong, transient electric fields adjacent to discrete aurora has previously been measured and were believed to be associated with bursts of electron precipitation (Lanchester et al., 1996).

The distance between the shear intensifications along the 1932 arc seen in the ASK images agrees with the mean distance between rays detected in the ALIS images (Fig. 4), implying that the rays are the result of the shear motion along the arc. Such rays, or intensifications, are different from rays such as those discussed in Ivchenko et al. (2005), which are isolated, distinct features moving independently of each other. The spacing of the intensifications can be compared with the properties of auroral "ruffs" described in Dahlgren et al. (2010), which were of similar scale sizes, although the wavelengths observed here are somewhat larger than the wavelengths of less than $3 \mathrm{~km}$ noted in that work. The ruffs were distinct from curls and folds, and it was proposed that their mechanism of formation is different in nature from these more reported auroral structures.

Auroral modelling and EISCAT electron densities were used by Lanchester et al. (1997) who found that the energy flux in a bright auroral arc was confined to a very narrow region of $100 \mathrm{~m}$ (much smaller than the radar beam width) of mostly monoenergetic electron precipitation, embedded in a wider region of lower flux and broader energy distribution. The narrow arcs in the present work are less bright than in that study, but are also found to be the result of an increase in flux. They too are narrower than the radar beam, so that there could be an underestimate of the total flux, here found to be $20 \mathrm{~mW} \mathrm{~m}^{-2}$. However, the improved optical measurements 
of the ASK detectors allow flux estimates at the pixel level, at which peak values of nearly double this estimate have been found in the arc.

Nonlinear Alfvén waves are believed to produce auroral forms with widths in the $0.1-10 \mathrm{~km}$ range (Stasiewicz et al., 2000). It was recently demonstrated that the electromagnetic fields supporting multi-scale discrete aurora are of an Alfvénic nature (Chaston et al., 2010). Chaston et al. (2003) concluded from their study of FAST data that auroral arcs caused by particle acceleration due to dispersive Alfvén waves have a typical width of $900 \mathrm{~m}$. Velocity shears in arcs are predicted to launch shear Alfvén waves, that will carry a downward Poynting flux. An increased energy flux is thus expected from this process.

Figure 12 (top) shows height profiles of the EISCAT electron density for the time interval around the 1932 arc, and the bottom panel is the corresponding modelled electron density. At 19:32:10 UT, just after the passage of the arc through the radar beam, a hole appears in the electron density measurements, at about $125 \mathrm{~km}$ altitude. Such a depletion indicates horizontal drifts of plasma out of the region of the radar beam due to Pedersen mobility, and thus strong electric fields (Palmer, 1995). A smaller bite-out can also be seen as the arc enters the beam, at about 19:32:04 UT. Such density depletions due to ionospheric plasma convection were also observed on the leading and trailing edges of an auroral arc, in the presence of large and variable electric fields, by Lanchester et al. (1998). In the inversion model, radar measurements are used to estimate the ionisation rate in the ionosphere. When solving the continuity equation, the convective term is typically neglected. Because of this, there are no bite-outs in the modelled data (Fig. 12, bottom). Thus, caution has to be taken with such a simplification, as it might lead to errors in the estimation of the ionization rate. For example, the peak in modelled average energy at 19:32:01 UT in the middle panel in Fig. 8 may be a result of strong convection. The implementation of corrections for such local convection effects is planned for future developments of the model.

The ASK cameras have been intensity calibrated by using the Pulkovo stellar catalogue, containing measured brightnesses of specific stars. The brightnesses in ASK are estimated to have deviations of up to $50 \%$. The main uncertainties are the background reduction and atmospheric conditions. When studying emission ratios rather than emissions from the individual channels some of the errors will be reduced. The systematic uncertainty in the modelled emission brightness is estimated to be $35 \%$ (Whiter et al., 2010), and the electron energies could be overestimated by up to a factor of 3. However, the good agreement between the ASK emissions and the modelled brightnesses retrieved from EISCAT data indicates that the uncertainty is smaller than this estimate. The energy variation across the thin auroral arcs, which is of main interest here, is also unaffected by any offset in the calibration of the data.

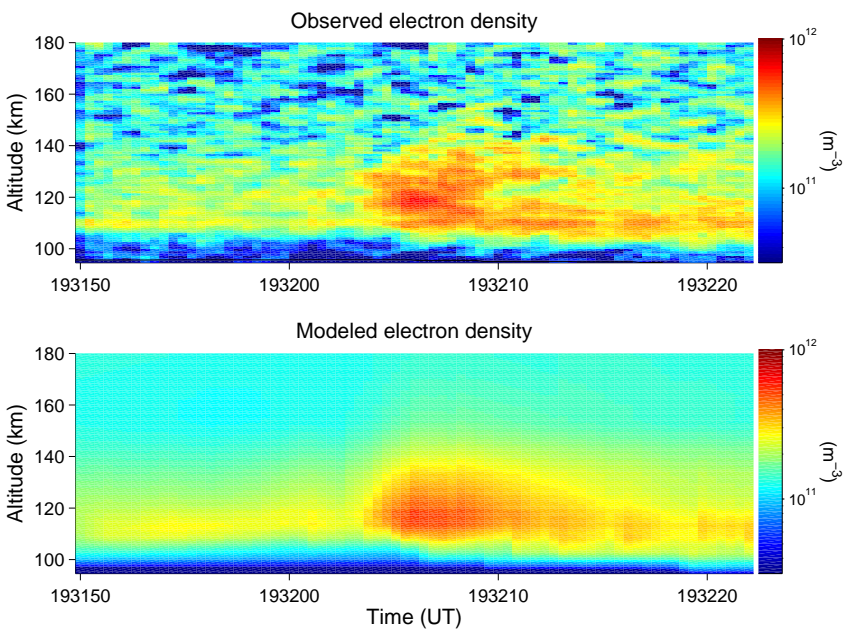

Fig. 12. Top: electron density profiles from EISCAT measurements, for the 1932 arc. Bottom: corresponding modelled electron density. The bite-out in the data at 19:32:10 UT is not reproduced by the model, and is believed to be caused by horizontal convection of plasma near the arc.

Note that for most times, even though the arcs are in the magnetic zenith, they do not fill the region of the radar beam uniformly. There will thus be an averaging effect when estimating the electron density in the two arcs and when modelling the energy of the precipitation based on the radar data. It is for fine-scale aurora, as well as for rapidly changing auroral structures such as those in this study, that the strength of multispectral imaging at high spatial and temporal resolution, combined with ion-chemistry modelling, becomes evident. Narrow arcs are not unusual in ground-based optical observations, but theoretical modelling is mostly applied to auroral arcs of several km widths.

\section{Summary}

The strength of combined optical and radar observations has been demonstrated for an auroral event on 12 December 2006. An interval of seven minutes was analysed, which included two north-south aligned auroral arcs.

A new time dependent inversion model is used to obtain estimates of the primary electron energy and flux from electron density measurements made with EISCAT. A very good agreement is found with the energies estimated from ASK optical data. The modelled energy-flux spectrogram in the arcs shows lower energies on the leading edges, and an enhancement in electron number flux during the passage of the arcs through the radar beam. The data can be interpreted as three different regions, containing populations with different average energies (between $1-10 \mathrm{keV}$ ); these energies are typical of diffuse particle precipitation caused by pitch-angle scattering. On the boundaries between these regions large and variable electric fields are formed, causing sheared arcs 
in the ionosphere. Shear Alfvén waves are launched in the boundary region, which increases the flux of the precipitating electrons.

In this study we were able to model the energy and flux across a very thin $(\sim 750 \mathrm{~m})$ auroral arc, and give a detailed energy map of the arc and its surroundings, simultaneously. Such techniques will be important when trying to understand the formation of auroral arcs and the associated current systems. Further studies of large electric fields associated with narrow auroral arcs are required to understand the relationship between currents and particle distributions.

\section{Appendix A}

\section{Estimating the precipitating electron spectrum from EISCAT observations}

In this section we describe an inversion model that estimates the spectra of precipitating auroral electrons in a parameter estimation problem, where a parameterized electron spectra is adapted to reproduce the observed electron density profiles. This is followed by a brief description of the ionisation profiles and calculations of the electron recombination. Finally, a short comparison of the strengths of this method compared to methods used previously, is given.

\section{A1 Model description}

To estimate the electron spectra, $I_{\mathrm{e}}(E, t, p)$, as a function of energy, $E$, at time $t$, we search for the electron spectrum that minimises the weighted least square difference between observed and modelled electron density, with an additional term penalising complexity of the parameterisation $p$ of the spectrum,

$$
\mathrm{AIC}=\log \left(\frac{1}{N} \sum_{j} \frac{\left(n_{\mathrm{e}}\left(t_{i}, z_{j}\right)-\tilde{n}_{\mathrm{e}}\left(t_{i}, z_{j}\right)\right)^{2}}{\sigma_{n_{\mathrm{e}}}^{2}}\right)+\frac{N+k}{N-k-2}
$$

where $n_{\mathrm{e}}\left(t, z_{j}\right)$ and $\tilde{n}_{\mathrm{e}}\left(t, z_{j}\right)$ are the observed and modelled electron density, respectively, at altitude $z_{j} ; \sigma_{n_{\mathrm{e}}}$ is the corresponding standard deviation of the electron density observations, $N$ is the number of altitudes with $n_{\mathrm{e}}$ observations and $k$ the total number of free parameters, $\bar{p}$, of the modelled electron spectra. The quantity calculated in Eq. (A1) is known as the Akaike information criterion (e.g. Burnham and Anderson, 2002), where the first term in Eq. (A1) decreases with increasing $k$, since a larger number of free parameters makes it possible to produce more complex electron spectra, leading to more small-scale variation in the ionisation profile; while the second term increases with $k$. For some $k$ a global minimum is obtained; additional free parameters are then not (statistically) justified by the improved fit to data.
The modelled electron density, $\tilde{n}_{\mathrm{e}}$, is obtained by integrating the electron continuity equation:

$$
\frac{\partial \tilde{n}_{\mathrm{e}}}{\partial t}=Q_{\mathrm{est}}(z, t)-\left(\alpha_{1} n_{\mathrm{NO}^{+}}+\alpha_{2} n_{\mathrm{O}_{2}^{+}}+\alpha_{3} n_{\mathrm{N}_{2}^{+}}\right) \tilde{n}_{\mathrm{e}}-\bar{v} \cdot \nabla \tilde{n}_{\mathrm{e}}
$$

with an ionisation profile $Q_{\text {est }}(z, t)$ calculated with the parameterized electron spectrum. Here $n_{s}$ is the density of species $s$ and $\bar{v}$ is the convective velocity of the plasma, which we assume is negligibly small.

The ionisation profile, $Q_{\text {est }}$ is calculated as a sum of ionisation profiles for monoenergetic precipitation scaled with the electron fluxes at those energies, or in matrix form (Sergienko and Ivanov, 1993; Rees, 1989; Semeter and Kamalabadi, 2005):

$Q_{\text {est }}(z, t)=A(z, E) \cdot I_{\mathrm{e}}(E, t, p)$

where the columns of $A(z, E)$ are altitude profiles of ionisation rate for mono-energetic precipitation with the corresponding peak energy, $E$.

The parameterisation of $I_{\mathrm{e}}(E, t, p)$ is an exponential of a cubic spline with $k / 2$ node points (each node of the spline has two free parameters, both the energy $E$ and the electron flux $I_{\mathrm{e}}(E)$ are allowed to vary). To search for the optimal $I_{\mathrm{e}}(E)$ we search over a range of $k$ from 6 to 18 , corresponding to 3 to 9 node points. The minimum AIC is typically found to have between 3 and 6 node points. To calculate properly the minimum AIC, all possible parameterizations such as box-car functions, polynomials, harmonic expansions etc. should be tested for each $k$, but the chosen parameterization is general enough to have the ability to reproduce most electron spectra accurately enough with a low number of free parameters.

The ionospheric electron loss processes are recombination and convection. When calculating the recombination term in Eq. (A2), ion densities modelled with the Southampton ionchemistry model are used, rather than densities from the empirical standard model International Reference Ionosphere (IRI). This gives more accurate estimates of the recombination, and in turn $I_{\mathrm{e}}(E)$, during periods of rapidly changing precipitation, when the ion composition is not in steady state but varies with time. The rates $\alpha$ at which electrons are recombining with different ionospheric species are

$\alpha_{1}=4.2 \times 10^{-13}\left(300 / T_{\mathrm{e}}\right)^{0.85} \mathrm{~m}^{3} \mathrm{~s}^{-1}$,

for $\mathrm{NO}^{+}$,

$\alpha_{2}=1.9 \times 10^{-13}\left(300 / T_{\mathrm{e}}\right)^{0.5} \mathrm{~m}^{3} \mathrm{~s}^{-1}$

for $\mathrm{O}_{2}^{+}$and

$\alpha_{3}=1.8 \times 10^{-13}\left(300 / T_{\mathrm{e}}\right)^{0.39} \mathrm{~m}^{3} \mathrm{~s}^{-1}$

for recombination with $\mathrm{N}_{2}^{+}$(Rees, 1989). The convection term is typically small, except for time periods around the 
passage of narrow auroral arcs. As the 1932 arc drifts out of the EISCAT UHF beam, the electron density decreases faster than can be explained by recombination. In Fig. 12 this can be seen as a more rapid decrease in $n_{\mathrm{e}}$ after 19:32:10 UT at altitudes between approximately 120 and $130 \mathrm{~km}$, where the ion mobility perpendicular to $B$ is at its largest.

\section{A2 Comparison with previous models}

Compared to other methods to invert electron density profiles to electron spectra (e.g. Semeter and Kamalabadi, 2005, and references therein) the method presented here provides a number of improvements. By not explicitly calculating the ionisation rate profiles from isolation of $Q$ in the electron continuity equation, which has been a standard method, the amplification of noise entering through the time derivative of the electron density and through the electron recombination terms is avoided. By this, combined with the smooth ionisation rate profiles obtained with the likewise smooth estimated electron spectra, we achieve noise damping, since only noise averaged over altitude propagates to the estimated electron spectra.

The minimum Akaike information criterion estimator automatically adjusts the number of free parameters in the description of the electron spectra to variations in measurement noise. A significant enough decrease in $\sigma$ in Eq. (A1) will increase the relative weight of the fit between the observed and modelled electron densities and shift the global minimum Akaike information criterion to a larger number of free parameters, $k$. This leads to an automatic adaption of the complexity of the spectral shape, correctly adjusting for variations in measurement noise, something that is difficult to achieve with other regularisation methods. Methods using predetermined shapes of the electron spectra, such as Maxwellian with variable peak energy and flux, will not be able to determine correctly the shape of spectra that deviate from the pre-selected shapes. Compared to regularised least square inversions, such as minimum length (Tichonov) or maximum entropy methods, the suggested method will return the simplest spectra - which will also be smooth; while the regularising terms in the Tichonov $\left(\sum_{i} I_{\mathrm{e}}\left(E_{i}\right)^{2}\right)$ and maximum entropy $\left(\left(\sum_{i} I_{\mathrm{e}}\left(E_{i}\right) \log I_{\mathrm{e}}\left(E_{i}\right)\right)\right)$ are both invariant to permutations in $I_{\mathrm{e}}\left(E_{i}\right)$ and do not explicitly enforce smoothness in the solution.

\section{Supplementary material related to this article is available online at: http://www.ann-geophys.net/29/1699/2011/ angeo-29-1699-2011-supplement.zip.}

Acknowledgements. ASK has been funded by PPARC and STFC of the United Kingdom, and the Swedish research council (VR). EISCAT is an international association supported by research organisations in China (CRIRP), Finland (SA), France (CNRS, till end 2006), Germany (DFG), Japan (NIPR and STEL), Norway (NFR),
Sweden (VR), and the United Kingdom (STFC). HD was partly funded by the National Science Foundation.

Topical Editor R. Nakamura thanks R. Michell and another anonymous referee for their help in evaluating this paper.

\section{References}

Aso, T., Ejiri, M., Urashima, A., Miyaoka, H., Steen, Å., Brändström, U., and Gustavsson, B.: First results of auroral tomography from ALIS-Japan multi-station observations in March, 1995, Earth, Planets, and Space, 50, 81-86, 1998.

Baker, D. J. and Romick, G. J.: The rayleigh: interpretation of the unit in terms of column emission rate or apparent radiance expressed in SI units, Appl. Optics, 15, 1966-1968, 1976.

Borovsky, J. E., Suszcynsky, D. M., Buchwald, M. I., and DeHaven, H. V.: Measuring the thicknesses of auroral curtains, Arctic, 44, 231-238, 1991.

Brändström, U.: The Auroral Large Imaging System - design, operation and scientific results, IRF Scientific Report 279, ISBN: 91-7305-405-4, PhD thesis, 2003.

Burnham, K. P. and Anderson, D.: Model Selection and Multimodel Inference: A Practical Information-Theoretic Approach, Springer-Verlag, 2 edn., 2002.

Chaston, C. C., Peticolas, L. M., Bonnell, J. W., Carlson, C. W., Ergun, R. E., McFadden, J. P., and Strangeway, R. J.: Width and brightness of auroral arcs driven by inertial Alfven waves, J. Geophys. Res., 108, doi:10.1029/2001JA007537, 2003.

Chaston, C. C., Seki, K., Sakanoi, T., Asamura, K., and Hirahara, M.: Motion of aurorae, Geophys. Res. Lett., 37, L08104, doi:10.1029/2009GL042117, 2010.

Dahlgren, H., Ivchenko, N., Sullivan, J., Lanchester, B. S., Marklund, G., and Whiter, D.: Morphology and dynamics of aurora at fine scale: first results from the ASK instrument, Ann. Geophys., 26, 1041-1048, doi:10.5194/angeo-26-1041-2008, 2008.

Dahlgren, H., Ivchenko, N., Lanchester, B. S., Ashrafi, M., Whiter, D., Marklund, G., and Sullivan, J.: First direct optical observations of plasma flows using afterglow of $\mathrm{O}^{+}$in discrete aurora, J. Atmos. Solar-Terr. Phys., 71, 228-238, doi:10.1016/j.jastp.2008.11.015, 2009.

Dahlgren, H., Aikio, A., Kaila, K., Ivchenko, N., Lanchester, B. S., Whiter, D., and Marklund, G.: First direct optical observations of plasma flows using afterglow of $\mathrm{O}^{+}$in discrete aurora, J. Atmos. Solar-Terr. Phys., 72, 633-637, doi:10.1016/j.jastp.2010.01.014, 2010.

Frey, H. U., Haerendel, G., Clemmons, J. H., Bochm, M. H., Vogt, J., Bauer, O. H., Wallis, D. D., Blomberg, L., and Lühr, H.: Freja and ground-based analysis of inverted-V events, J. Geophys. Res., 103, 4303-4314, doi:10.1029/97JA02259, 1998.

Gordon, R. and Herman, G. T.: Three-dimensional reconstruction from projections; a review of algorithms, Int. Rev. Cytol., 38 , 111-151, 1974.

Gustavsson, B.: Tomographic inversion for ALIS noise and resolution, J. Geophys. Res., 103, 26621-26632, 1998.

Gustavsson, B.: Three dimensional imaging of aurora and airglow, $\mathrm{PhD}$ thesis, 2000.

Gustavsson, B., Steen, Å., Sergienko, T., and Brändström, B. U. E.: Estimate of auroral electron spectra, the power of ground-based multi-station optical measurements, Phys. Chem. Earth, 26, 189194, doi:10.1016/S1464-1917(00)00106-9, 2001. 
Hecht, J. H., Christensen, A. B., Strickland, D. J., and Meier, R. R.: Deducing composition and incident electron spectra from ground-based auroral optical measurements: Variation in oxygen density, J. Geophys. Res., 94, 13553-13563, 1989.

Hunten, D. M., Roach, F. E., and Chamberlain, J. W.: A photometric unit for the airglow and aurora, JATP, 8, 345-346, 1956.

Ivchenko, N., Blixt, E. M., and Lanchester, B. S.: Multispectral observations of auroral rays and curls, Geophys. Res. Lett., 32, L18106, doi:10.1029/2005GL022650, 2005.

Johansson, T., Marklund, G., Karlsson, T., Lilo, S., Lindqvist, P.-A., Marchaudon, A., Nilsson, H., and Fazakerley, A.: On the profile of intense high-altitude auroral electric fields at magnetospheric boundaries, Ann. Geophys., 24, 1713-1723, doi:10.5194/angeo24-1713-2006, 2006.

Lanchester, B. S., Palmer, J. R., Rees, M. H., Lummerzheim, D., Kaila, K., and Turunen, T.: Energy flux and characteristic energy of an elemental auroral structure, Geophys. Res. Lett., 21, 27892792, 1994.

Lanchester, B. S., Kaila, K., and McCrea, I. W.: Relationship between large horizontal electric fields and auroral arc elements, J. Geophys. Res., 101, 5075-5084, doi:10.1029/95JA02055, 1996.

Lanchester, B. S., Rees, M. H., Lummerzheim, D., Otto, A., Frey, H. U., and Kaila, K. U.: Large fluxes of auroral electrons in filaments of 100 m width, J. Geophys. Res., 102, 9741-9748, 1997.

Lanchester, B. S., Rees, M. H., Sedgemore, K. J. F., Palmer, J. R., Frey, H. U., and Kaila, K. U.: Ionospheric response to variable electric fields in small-scale auroral structures, Ann. Geophys., 16, 1343-1354, doi:10.1007/s00585-998-1343-8, 1998.

Maggs, J. E. and Davis, T. N.: Measurements of the thicknesses of auroral structures, Planet. Space Sci., 16, 205-209, 1968.

Meier, R. R., Strickland, D. J., Hecht, J. H., and Christensen, A. B.: Deducing composition and incident electron spectra from ground-based auroral optical measurements: A study of auroral red line processes, J. Geophys. Res., 94, 13541-13552, 1989.

Palmer, J. R.: Plasma density variations in aurora, PhD thesis, 1995.

Rees, M.: Physics and chemistry of the upper atmosphere, Cambridge University Press, 1989.

Roth, M., Evans, D. S., and Lemaire, J.: Theoretical structure of a magnetospheric plasma boundary - Application to the formation of discrete auroral arcs, J. Geophys. Res., 98, 11411-11423, doi:10.1029/93JA00156, 1993.
Sandahl, I., Sergienko, T., and Brändström, U.: Fine structure of optical aurora, J. Atmos. Solar-Terr. Phys., 70, 2275-2292, 2008.

Semeter, J. and Kamalabadi, F.: Determination of primary electron spectra from incoherent scatter radar measurements of the auroral E region, Radio Sci., 40, RS2006, doi:10.1029/2004RS003042, 2005.

Semeter, J., Lummerzheim, D., and Haerendel, G.: Simultaneous multispectral imaging of the discrete aurora, J. Atmos. SolarTerr. Phys., 63, 1981-1992, 2001.

Semeter, J., Zettergren, M., Diaz, M., and Mende, S.: Wave dispersion and the discrete aurora: New constraints derived from high-speed imagery, J. Geophys. Res., 113, A12208, doi:10.1029/2008JA013122, 2008.

Sergienko, T. I. and Ivanov, V. E.: A new approach to calculate the excitation of atmospheric gases by auroral electron impact, Ann. Geophys., 11, 717-727, 1993.

Sergienko, T., Sandahl, I., Gustavsson, B., Andersson, L., Brändström, U., and Steen, Å.: A study of fine structure of diffuse aurora with ALIS-FAST measurements, Ann. Geophys., 26, 3185-3195, doi:10.5194/angeo-26-3185-2008, 2008.

Stasiewicz, K., Bellan, P., Chaston, C., Kletzing, C., Lysak, R., Maggs, J., Pokhotelov, O., Seyler, C., Shukla, P., Stenflo, L., Streltsov, A., and Wahlund, J.-E.: Small scale Alfvénic structure in the aurora, Space Sci. Rev., 92, 423-533, 2000.

Strickland, D. J., Meier, R. R., Hecht, J. H., and Christensen, A. B.: Deducing composition and incident electron spectra from ground-based auroral optical measurements. I - Theory and model results. II - A study of auroral red line processes. III - Variations in oxygen density, J. Geophys. Res., 94, 13527-13539, 1989.

Trondsen, T. S. and Cogger, L. L.: Fine-scale optical observations of aurora, Phys. Chem. Earth, 26, 179-188, 2001.

Whiter, D. K., Lanchester, B. S., Gustavsson, B., Ivchenko, N., and Dahlgren, H.: Using multispectral optical observations to identify the acceleration mechanism responsible for flickering aurora, J. Geophys. Res., 115, A12315, doi:10.1029/2010JA015805, 2010. 